\title{
In Vitro Studies of Some Medicinal Plants Extracts for Antiviral Activity against Rotavirus
}

\author{
Zakia F. S. AL-Ballawi ${ }^{1 *}$, Nezar A. Redhwan ${ }^{1}$ and Mohamed Ali ${ }^{2}$ \\ ${ }^{1}$ Biology Department, Faculty of Science, King Abdulaziz University, Jeddah, Saudi Arabia, \\ ${ }^{2}$ Center of Excellence for Influenza viruses, National Research Centre, Egypt
}

\begin{abstract}
Every year, Rotavirus infection is responsible for over 600,000 childhood deaths worldwide, occurring mainly in developing countries in addition to infections of elderly people in nursing homes and compromised patients. In this study, we investigated in vitro antiviral activity of aqueous extracts of some medicinal plants including, garlic bulbs (Allium Sativum), ginger rhizomes (Zingiber officinale), pomegranate peel (Punica granatum) and Lemongrass leaves (Cymbopogon citratus) against rotavirus. The study was carried out using multiple approaches both at cellular level using cell live MA-104 such as the Plaque assay which used for determining the quantity of infectious virus and the MTT test (3-4,5-dimethythiazol-2yl)-2,5diphenyl tetrazolium bromide) to estimate the cytotoxicity of the tested plant extracts. The results showed that the dilutions of crude extracts of Allium sativum gave mean inhibition percentage for rotavirus of $73.33 \%$ while Zingiber officinale gave 68.33\%, Cymbopogon citrates gave 67.33\% and Punica granatum gave 65\% inhibited. All plants extract showed antiviral activities but statistically no significant differences of antiviral activity were found among these plant extracts. These findings suggested that the anti-rotaviral activity might be owing to the presence of various compounds such as flavonoids, terpenes, polyphenolic derivatives and other compounds that have been documented to possess antiviral properties.
\end{abstract}

Keywords: Medicinal plants, Antiviral, Rotavirus, Cymbopogon citrates, Punica granatum, Zingiber officinale,

\section{Introduction}

The name rotavirus (RV) came from the Latin word "rota" for wheel and is given because the viruses have a distinct wheel-like shape. Rotaviruses occur throughout the world is the leading cause of severe diarrhea in children and since 1973, human rotavirus is still one of the leading causes of severe dehydrating diarrhea in young children which caused deaths of more than 600,000 children under the age of five years worldwide. Deaths from rotavirus are most prevalent in developing nations, where patients may not always receive adequate medical attention quickly enough. Rotavirus infection occurs primarily in the differentiated enterocytes of the jejunum in the small intestine, which are responsible for digestion and absorption and destruction of these cells results in the loss of nutrient and water absorption, followed by dehydration and malnutrition that ultimately can lead to death (Pesavento et al., 2006; Knipping et al., 2012).

Rotavirus infection is also known as infantile diarrhea or winter diarrhea, because it mainly targets infants and young children. The outbreaks are usually in the cooler months of winter. The virus is classified into different groups (Group A through group G), depending on the type of protein marker (antigen) that is present on its surface. The diarrheal infection of children is caused by the group A rotaviruses. Group B rotaviruses have caused major epidemics of adult diarrhea in China. Group C rotavirus has been associated with rare cases of diarrheal outbreaks in Japan and England. Groups D through G have not been detected in humans. They are responsible for the majority of childhood morbidity and mortality from viral gastroenteritis. The younger the child is the more severe the symptoms. Comparing to other viruses or bacteria, it accounts for 40 to 50 percent of diarrhea cases (Bishop et al., 1973, Ahmed et al., 1991, Bern et al., 1992).

The only known treatment for rotavirus gastroenteritis is supportive therapy, the replacement of fluids and electrolytes lost by diarrhea. In 1999, a first generation of 52 licensed rotavirus vaccines in the United States was obtained but Rota Shield was withdrawn from the market a year after introduction due to a possible correlation between vaccine application and the occurrence of intussusceptions. In 2006, two oral, attenuated, reassortant rotavirus vaccines (Rota Rix and RotaTeq) that prevent rotavirus infections in infants and young children were tested, but they haven't been approved for infants with immunosuppressive illnesses and also in populations at the greatest risk in developing countries such as Asia and Africa (Cecilio et al., 2012). However, rotavirus vaccines are expensive and may not be affordable for the developing world at present, compromising full vaccine coverage. Therefore, there is growing interest in the search for novel compounds for the treatment of diarrheal diseases as well as alternative methods to control rotavirus infection. Despite the advances made with synthetic products, natural compounds either pure compounds or as extracts derived from plants which are used in traditional medicine have been recognized as ideal candidates as antiviral agents. Furthermore, the study 
of medicinal plants based on popular use, can provide useful information for the discovery of new drugs with less financial burden. Also, the biological diversity of nature is the source of a wide range of bioactive molecules (De Clercq, 2005). It is known that secondary metabolites have a wide spectrum of biological activities, including potential antiviral effect (Goncalves et al., 2005; Palombo, 2006).

Many viral infections can be cured by some medicinal herbs because they contain antiviral agents that either kill the virus, or interfere with the virus-host-cell replication cycle to interrupt viral replication or to support immune defense. Previous studies investigated the antiviral activity of several plant extracts against rotavirus. Chingwaru et al. (2011) reported high in vitro inhibition of rotavirus by Tylosema esculentum (marama) which are used as food and as a traditional medicine against diarrhea in Southern Africa. Also, fourteen Brazilian medicinal plants traditionally used for the treatment of diarrhea were investigated for their activity against rotavirus. Among the species studied Byrsonima verbascifolia, Eugenia dysenterica, Hymenaea courbaril and Myracrodruon urundeuva displayed potential activity against rotavirus (Cecilio et al., 2012). Moreover, Taherkhani et al. (2013) reported that Achillea kellalensis extracts which is frequently used in Iran as a traditional herbal medicine for the treatment of acute diarrhea, exert potent antirotaviral activity only after viral adsorption. In contrast, the human rotavirus was not inhibited by the essential oil of Lippia graveolens (Maxican oregano) (Pilau et al., 2011).

Over the past few decades, many medicinal plants are used in Saudi Arabia to treat many pathogens including chicken pox, Japanese encephalitis virus, influenza virus, HSV-1 and 2, tobamovirus, HIV, African Swine Fever Virus (ASFV), polyhedrosis virus, hepatitis A virus and feline leukaemia virus.

The aim of the present study was determination of the antivirus activity of some plant extracts used traditionally in Saudi Arabia to treat Virus infections.

\section{Virus Stocks:}

\section{Material and Methods}

Both Rotavirus SA-11 and African Rhesus monkey kidney MA-104 cell line were provided by Prof. Mohamed Ali, Center of Excellence for Influenza viruses, National Research Centre, Egypt.

\section{Plant Materials:}

Fresh samples of garlic bulbs (Allium sativum), ginger rhizomes (Zingiber officinale), pomegranate (Punica granatum) and lemongrass leaves (Cymbopogon citratus) were collected from Jeddah market, Saudi Arabia during summer 2011 and identified at the Biology Department, Faculty of Sciences, KAU, Jeddah, Saudi Arabia. The plant materials were extracted using water and the obtained extracts were lypholized and different concentrations were prepared, $25 \mu \mathrm{g} / \mu \mathrm{l}, 50 \mu \mathrm{g} / \mu \mathrm{l}$ and $100 \mu \mathrm{g} / \mu \mathrm{l}$ of dry plant powder (Van Verma et al., 2008).

\section{Antiviral activity measured using Plaque reduction assa:}

Antiviral activity assay was carried out according to the method of Hayden et al., (1980) in a six well plate where MA-104 cell line $\left(10^{5}\right.$ cells / ml $)$ were cultivated for 24 hrs at $37^{\circ} \mathrm{C}$. Rotavirus SA-11 was diluted to give $10^{5} \mathrm{PFU} /$ well and mixed with the safe concentration of the tested compound, and the mixture were incubated for 30 minutes at $37^{\circ} \mathrm{C}$ before being added to the cells. Growth medium was removed from the cell culture plates and virus-Cpd or virus-extract and Virus-oseltamivir mixtures were inoculated (100 $\mu \mathrm{l} /$ well), After 1 hour contact time for virus adsorption, $3 \mathrm{ml}$ of DMEM supplemented with $2 \%$ agarose was added onto the cell monolayer and plates were left to solidify followed by incubation at $37^{\circ} \mathrm{C}$ till formation of viral plaques (3 to 4 days). Formalin (10\%) was added for two hours then plates were stained with $0.1 \%$ crystal violet in distilled water. Control wells were included where untreated virus was incubated with MDCK cells and finally plaques were counted and percentage of reduction in plaques formation in comparison to control wells was recorded as following :

$\%$ of inhibition= viral count (untreated) - viral count (treated)/viral count (untreated) $\mathrm{x} 100$.

\section{Results}

The antiviral activities of the tested plant extracts were examined against rotavirus SA-11 replication in MA-104 cells. Different concentrations of Allium sativum, Zingiber officinale, Punica granatum and Cymbopogon citrates extracts, $25 \mu \mathrm{g} / \mu \mathrm{l}, 50 \mu \mathrm{g} / \mu \mathrm{l}$ and $100 \mu \mathrm{g} / \mu \mathrm{l}$ were prepared and tested. The inhibition percentages of rotavirus for each plant extract were determined ((Table 1 and Figure 1). The aqueous extracts of all tested plants extracts showed inhibition effect to rotavirus. The results showed that different concentrations of Allium sativum crude extracts $(25,50$ and $100 \mu \mathrm{g} / \mu \mathrm{l})$ inhibited rotavirus by $69 \%, 71 \%$ and $80 \%$, respectively. The mean inhibition percentage for Allium sativum was $73.33 \%$. Similarly, Zingiber officinale gave the highest inhibition effect on rotavirus with inhibition percentages of $76 \%, 68 \%$ and $61 \%$, respectively for the three tested concentrations with mean inhibition percentage of $68.33 \%$. On the other hand, Punica granatum inhibited rotavirus by $68 \%, 65 \%$ and $61 \%$, respectively for the three tested concentrations and the 
mean inhibition percentage of $65 \%$. The different tested concentrations of Cymbopogon citrates plant extract inhibited rotavirus by $66 \%, 66 \%$ and $70 \%$, respectively with mean average of inhibition of $67.33 \%$. The obtained results of comparing the mean inhibition percentages of Allium sativum, Zingiber officinale, Cymbopogon citrates and Punica granatum showed that Allium sativum gave the highest inhibition73.33\%, followed by Zingiber officinale $68.33 \%$, Cymbopogon citrates $67.33 \%$ and Punica granatum 65\% as shown in Figure 2 .

\section{Discussion}

Human rotavirus is one dangerous virus that cause severe dehydrating diarrhea in young children followed by deaths in children under the age of five years, especially in developing ountries, where patients may not always receive adequate medical attention quickly enough. Rotavirus infection was mainly in the small intestine where food digestion and absorption were occurred. Destruction of these cells caused nutrient and water loss, dehydration, malnutrition and death ( Pesavento et al., 2006; Knipping et al., 2012) and replacement of fluids and electrolytes is quickly needed. Using the rotavirus to treat rotavirus have some problems (Cecilio et al., 2012), expensive and may not be affordable for the developing world. Thus, searching for novel compounds for the treatment of diarrheal diseases as well as alternative methods to control rotavirus infection is needed. Synthetic antiviral agents were not the best compared to natural compounds either pure compounds or as extracts derived from plants used in traditional medicine. It is well known that secondary metabolites of many plants have a wide spectrum of biological activities, including potential antiviral effect (Goncalves et al., 2005; Palombo, 2006). Furthermore, the effect of most used popular plants may led to new effective antivirus drugs and the bioactive material can be isolated from the plant and identified (De Clercq, 2005).

The antiviral activity of several plant extracts against rotavirus was reported Chingwaru et al. (2011) and inhibition of rotavirus by Tylosema esculentum (marama) in vitro was reported. In Brazilian, Byrsonima verbascifolia, Eugenia dysenterica, Hymenaea courbaril and Myracrodruon urundeuva which were used traditionally for treatment of diarrhea displayed potential activity against rotavirus (Cecilio et al., 2012). Moreover in Iran, Achillea kellalensis extract which is frequently used as a traditional herbal medicine for the treatment of acute diarrhea, showed potent antirotaviral activity only after viral adsorption (Taherkhani et al., 2013). In contrast, Pilau et al., 2011 reported that the human rotavirus was not inhibited by the essential oil of Lippia graveolens (Maxican oregano).

In present study, the activity of the water extracts of some plants against rotavirus SA 11 in vitro was determined. Therefore, the four tested plants were belonging to different families and the tested plants were extracted and screened for their antiviral activity against rotavirus. These plants were garlic (Allium sativum), ginger (Zingiber officinale), pomegranate Peel (Punica granatum) and lemongrass (Cymbopogon citrates). The results are scheduled in the (Table 1) clearly indicated that these plant extracts under investigation showed potential activity against rotavirus SA-11 and must be selected for further studies. Some phytochemical, biological and antimicrobial studies with these four active plants have been reported in literature (Ravinder $e t$ al., 2010; Bhowmik et al., 2013; Gebreyohannes and Gebreyohannes, 2013; Nandi et al., 2013). In contrast, limited studies have been conducted on the antiviral activities associated with our tested plants. Among the viruses which are sensitive to garlic extracts are the Human Cytomegalovirus (CMV), influenza B, Herpes Simplex Virus type 1(HSV-1), Herpes Simplex Virus type 2 (HSV-2), parainfluenza virus type 3, vaccinia virus, vesicular stomatitis virus, and Human Rhinovirus type 2 (HRV-2) (Tsai et al., 1985). In case of ginger, it was found that the aqueous extract of ginger showed an inhibition against HCV, Hepatitis C virus (El-Adawi et al., 2011). Meanwhile, the antiviral activities of pomegranate against some viruses, such as influenza virus, herpes virus, poxviruses, and Human Immunodeficiency (HIV-1), have been reported (Neurath et al., 2005; Kotwal, 2008; Haidari et al., 2009). Furthermore, lemongrass was among medicinal plants which showed a clear inhibition of Dengue virus serotype 1 (Tang et al., 2012). To our knowledge, none of these plants have been reported before to have antiviral action against rotaviruses. As the main objective in this study was to perform a rapid screening of the potential activity of these extracts against rotavirus, rhesus monkey kidney (MA-104) cells were used for viral culture. MA-104 cells are the most used cells in experiments with rotavirus due to their susceptibility to this virus, and their ability to show typical cytopathic and cytotoxic effects easily, identified by inverted optical microscopy within short time (Andres et al., 2007; Cecilio et al., 2012).

A consensus protocol for antiviral susceptibility testing is not available, thus several different techniques based on cythopathic effect or cell viability are applied to investigate antiviral activity (Swierkosz and Hodinka, 1999). The colorimetric assay with MTT which was based on the reduction of the tetrazolium dye was used to measure cell viability. The previous method has been employed to access antiviral activity against different human viruses. Studies comparing plaque reduction assays and MTT did not find significant difference in the results for both adenovirus and Human Herpes Virus type 1(HHV-1) (Freitas et al., 2009). In general, all plant extracts showed no cytotoxicity to the tested cell culture, which was expected, where these genera are already used by the population to treat some diseases and the aqueous extracts of all tested plants exhibited 
inhibition effect against rotavirus. These findings suggested that the anti-rotaviral activity might be owing to the presence of various compounds such as flavonoids, terpenes, polyphenolic derivatives and other compounds that have been documented to possess antiviral properties. Garlic extracts contained allicin and ajoene which are known to be the main active compounds with in vitro and in vivo antiviral activity (Ankri and Mirelman, 1999). Also, the antiviral activity of ginger may be attributed to the presence of several compounds with antiviral activity such as phenolic derivatives including gingerol, paradole, bisabolene, zingerone, zingiberol and 6-shogaol (Mishra et al., 2012) in addition to sesquiterpenes such $\beta$ - sesquiphellandrene which is the most active of them (Malhotra and Singh, 2003; Rehman et al., 2011 ). Moreover, the hydrolysable tannins and anthocyanins are the main compounds that are suggested to be responsible for the antiviral activity of pomegranates (Parseh et al., 2012; Howell and D'Souza, 2013). Kasimsetty et al., (2009) reported that among four flavonoid compounds (ellagic acid, caffeic acid, luteolin, and punicalagin) associated with pomegranates, only punicalagin was have inhibitory effects on influenza virus. Meanwhile, the antiviral activity of lemongrass might be owing to the presence of Flavonoid compounds: luteolin, apigenin, homoorintine, flavanoides and its 2-Orhamnosil-limborientino or other compounds such as terpenes and polyphenols (Tang et al., 2012). In addition, flavonoids are the most ubiquitous phenolic compounds found in nature, showing a range of pharmacological activities, including antiviral action (Bae et al., 2000; Cushnie and Lamb, 2005; Friedman, 2007; Savi et al., 2010; Ozcelik et al., 2011). For example, Momordica charantia has activity against HSV-1, polio type 1, parainfluenza and respiratory syncytial virus due to the presence of flavonoids such as lutelin, kampherol and quercetin (Tang et al., 2012). Previous studies have demonstrated that some flavonoids were able to inhibit rotavirus propagation, as well as protect the cell cultures against virus invasion (Bae et al., 2000). There are two probable pathways that could be the mode of antiviral action: 1) Interference with viral adsorption, and 2) Inhibition of viral replication. Schnitzler et al., (2008) noted that pre-treatment of the cells might give the cells protective effects against viruses by preventing viral adsorption. It is reported that flavonoids are able to inhibit viruses by inhibiting different pathways like inhibition of dehydroandrographolide succinate monoester (DASM) which interfere with cell fusion, thus preventing HIV from entering the cell. Meanwhile, certain flavonoids with potent anti-HIV effects are capable of inhibiting virus through inhibition of reverse transcriptase and even cellular DNA or RNA polymerase (Tang et al., 2012). Although a number of publications have focused on the isolation and identification of bioactive compounds it is important to keep in mind the complexity of plants and a single compound may not be responsible for the observed activity but rather a combination of compounds (either minor or major) interacting in an additive or synergistic manner (Van Vauren, 2008). In conclusion, many plant extracts may showed inhibitory effect on rotavirus but this field still need many studies to determine the most active plants and their mode of actions.

\section{References}

[1]. Ahmed MU, Urasawa S, Taniguchi K, Urasawa T, Kobayashi N, Wakasugi F, (1991). Analysis of human rotavirus strains prevailing in Bangladesh in relation to nationwide floods brought by the 1988 monsoon. J Clin Microbiol; 29:2273-9

[2]. Bern, C., Martines, J. de Zoysal, I and Glass. R. I. (1992). The magnitude of the global problem of diarrhoeal disease: a ten-year update. Bull. W. H. O. 70:705-714.

[3]. Andres, A., Donovan, S.M.; Kuhlenschmidt, T.B. and Kuhlenschmidt, M.S. (2007). Isoflavones at concentrations present in soy infant formula inhibit rotavirus infection in vitro. The Journal of Nutrition, 2068-2073.

[4]. Ankri, S. and Mirelman, D. (1999). Antimicrobial properties of allicin from garlic. Microbes and Infection, 2:125-129.

[5]. Bae, E. A.; Han, M. J.; Lee, M. and Kim, D. H. (2000). In vitro inhibitory effect of some flavonoids on rotavirus infectivity. Biological and Pharmaceutical Bulletin, 23:1122- 1124.

[6]. Bhowmik, D.; Gopinath, H.; Kumar, B. P.; Duraive, S.; Aravind, G. and Kuma, K.P.S. (2013). Medicinal uses of Punica granatum and its health benefits. Journal of Pharmacognosy and Phytochemistry, 1(5):28-35.

[7]. Bishop, R. F., G. P. Davidson, I. H. Holmes, and B. J. Ruck. 1973. Virus particles in epithelial cell of duodenal mucosa from children with viral gastroenteritis. Lancetii:1281-1283.

[8]. Cecilio, A. B.; de Fariaa, D. B.; Oliveiraa, P. D.; Caldasa, S.; de Oliveirab, D. A.; Sobralc, M. E. G.; Duartea, M. G. R.; Moreiraa, C. P. D.; Silva, C. G. and de Almeidaa, V.L. (2012). Screening of Brazilian medicinal plants for antiviral activity against rotavirus. Journal of Ethnopharmacology, 141:975 - 981.

[9]. Chingwaru, W.; Majinda, R. T.; Yeboah, S. O.; Jackson, J. C.; Kapewangolo, P. T.; Kandawa-Schulz, M. and Cencic, A. (2011) Tylosema esculentum (Marama) tuber and Bean extracts are strong antiviral agents against rotavirus infection. Evidence-Based Complementary and Alternative Medicine, 2011:1-11.

[10]. Cushnie, T. P. T. and Lamb, A. J. (2005). Review antimicrobial activity of flavonoids. International Journal of Antimicrobial Agents, 26:343-356.

[11]. De Clercq, E. (2005). Recent highlights in the development of new antiviral drugs. Current Opinion in Microbiology, 8:552-608.

[12]. El-Adawi, H.; El-Demellawy, M. and El-Wahab, A. A. (2011). Some medicinal plant extracts exhibit potency against viral Hepatitis C. Journal of Bioscience and Technology, 2(1):223-231.

[13]. Freitas, A. M.; Almeida, M. T. R.; Andrighetti-Frohner, C. R.; Cardozo, F. T. G. S.; Barardi, C. R. M.; Farias, M. R. and Simoes, C. M. O. (2009). Antiviral Activityguided fractionation from araucaria angustifolia leaves extract. Journal of Ethnopharmacology, 126(3):512-517.

[14]. Friedman, M. (2007). Overview of antibacterial, antitoxin, antiviral, and antifungal activities of tea flavonoids and teas. Molecular Nutrition and Food Research, 51(1):116-150.

[15]. Gebreyohannes, G. and Gebreyohannes, M. (2013). Medicinal values of garlic: a review. International Journal of Medicine and Medical Sciences, 5(9):401-408. 
[16]. Goncalves, J. L.; Lopes, R. C.; Oliveira, D. B.; Costa, S. S.; Miranda, M. M.; Romanos, M. T.; Santos, N.S. and Wigg, M.D. (2005). In vitro anti-rotavirus Activity of some medicinal plants used in Brazil against diarrhoea. Journal of Ethnopharmacology, 99:403-407.

[17]. Haidari, M.; Ali, M.; Casscells, W. S. and Madjid, M. (2009). Pomegranate (Punica granatum) purified polyphenol extract inhibits influenza virus and has a synergistic effect with oseltamivir. Phytomedicine, 16(12):1127-1163.

[18]. Howell, A. B. and D'Souza, D. H. (2013). The pomegranate: effects on bacteria and viruses that influence human health. Evidence-Based Complementary and Alternative Medicine, 2013:1-11.

[19]. Kasimsetty, S. G.; Bialonska, D.; Reddy, M. K.; Thornton, C.; Willett, K. L. and Ferreira, D. (2009). Effects of pomegranate chemical constituents/intestinal microbial metabolites on CYP1B1 in 22Rv1 prostate cancer cells. Journal of Agricultural and Food Chemistry, 57(22):10636-10644.

[20]. Knipping, K.; Garssen, J. and van't Land, B. (2012) An evaluation of the inhibitory effects against rotavirus infection of edible plant extracts. Virology Journal, 9:137- 144.

[21]. Kotwal, G.J. (2008) Genetic diversity-independent neutralization of pandemic viruses (e.g.HIV), potentially pandemic (e.g. H5N1 strain of influenza) and carcinogenic (e.g.HBV and HCV) viruses and possible agents of bioterrorism (variola) by enveloped virus neutralizing compounds (EVNCs). Vaccine, 26:3055-3058

[22]. Malhotra, S. and Singh, A. P. (2003) Medicinal properties of (Zingiber officinale Rosc.). Natural Product Radiance, 2(6):296-301.

[23]. Mishra, R. K.; Kumar, A. and Kumar, A. (2012) Pharmacological activity of Zingiber officinale. International Journal of Pharmaceutical and Chemical Sciences, 1(3):1073-1078.

[24]. Nandi, S.; Saleh-e-In, M.; Rahim, M.; Bhuiyan, N. H.; Sultana, N.; Ahsan, A.; Ahmed, S.; Siraj, S.; Rahman, Z. and Roy, S. K. (2013) Quality composition and Biological significance of the Bangladesh and China ginger (Zingiber officinale Rosc.). The Journal of Microbiology, Biotechnology and Food Sciences, 2(5):2283-2290.

[25]. Neurath, A. R.; Strick, N.; Li, Y. and Debnath, A. K. (2005). Punica granatum (pomegranate) juice provides an HIV-1 entry inhibitor and candidate topical microbicide. Annals of the New York Academy of Sciences, 1056:311-327.

[26]. Ozcelik, B.; Kartal, M. and Orhan, I. (2011). Cytotoxicity, antiviral and antimicrobial activities of alkaloids, flavonoids, and phenolic acids. Pharmaceutical Biology, 49:396-402.

[27]. Palombo, E. A. (2006). Phytochemicals from traditional medicinal plants used in the treatment of diarrhoea:modes of action and effects on intestinal function. Phytotherapy Research, 20:717-724

[28]. Parseh, H.; Shahin, H.; Emam-djome, Z. and Lavasani, A. S. (2012). Antimicrobial properties of pomegranate (Punica granatum L.) as a tannin rich fruit: a review. The 1st International and The 4th National Congress on Recycling of Organic Waste in Agriculture, Isfahan, Iran, 26-27/4/2012.

[29]. Pesavento, J. B.; Crawford, S. E.; Estes, M. K. and Prasad, B. V. (2006). Rotavirus proteins: structure and assembly. Current Topics in Microbiology and Immunology, 309:189-219.

[30]. Pilau, M. R.; Alves, S. H.; Weiblen, R.; Arenhart, S.; Cueto, A. P. and Lovato, L. T. (2011). Antiviral activity of the Lippia graveolens (Mexican Oregano) essential oil and its main compound carvacrol against human and animal viruses. Brazilian Journal of Microbiology, 42:1616-1624.

[31]. Ravinder, K.; Pawan, K.; Gaurav, S.; Paramjot, K.; Gagan, S. and Appramdeep, K. (2010). Pharmacognostical investigation of Cymbopogon citratus (DC) Stapf. Der $\quad$ Pharmacia Lettre, 2(2):181-189.

[32]. Rehman, A. R. M.; Naveed, A.; Jabeen, Q,; saeed, T.; Ali Shah, S. M.; Khalil Ahmed, Shaheen, G.; and Asif, H. M. (2011). Zingiber officinale Roscoe (pharmacological activity). Journal of Medicinal Plants Research, 5(3):344-348.

[33]. Savi, L. A.; Caon, T.; de Oliveira, A. P.; Sobottka, A. M.; Werner, W.; Reginatto, F. H.; Schenke, E. P.; Barardi, C. R. and Simoes, C. M. (2010) Evaluation of antirotavirus activity of flavonoids. Fitoterapia, 81(8):1142-1147.

[34]. Schnitzler, P.; Schneider, S.; Stintzing, F. C.; Carle, R. and Reichling, J. (2008). Efficacy of an aqueous pelargonium sidoides extract against herpesvirus. Phytomedicine, 15:1108-1116.

[35]. Swierkosz, E. M. and Hodinka, R. L. (1999). Antiviral agents and susceptibility tests. In: Murray, P. R.; Baron, E. J.; Pfaller, M. A.; Tenover, F. C.; Yolken, R. H.; editors. Manual of clinical microbiology. Washington, DC: American Society for Microbiology, 1624-1639.

[36]. Taherkhani, R.; Farshadpour, F. and Makvandi, M. (2013). In Vitro anti-rotaviral activity of Achillea kellalensis. Jundishapur Journal of Natural Pharmaceutical Products, 8(3):138-181.

[37]. Tang, L. I. C.; Ling, A. P. K.; Koh, R. Y.; Chye, S. M. and Voon, K. G. L. (2012). Screening of anti-dengue activity in methanolic extracts of medicinal plants. Complementary and Alternative Medicine, 12:3-12

[38]. Tsai, Y.; Cole, L. L.; Davis, L. E.; Lockwood, S. J.; Simmons, V. and Wild, G. C. (1985). Anti viral properties of garlic:in vitro effects of influenza B, herpes simplex virus, and coxsackie viruses. Planta Medica, 5:460-461.

[39]. Van Vauren, S. F. (2008). Antimicrobial activity of south african medicinal plants. Journal of Ethnpharmacology, 119:462-472.

TABLE 1. Inhibitory Percentage of the Tested Plant Extracts Against Rotavirus SA-11

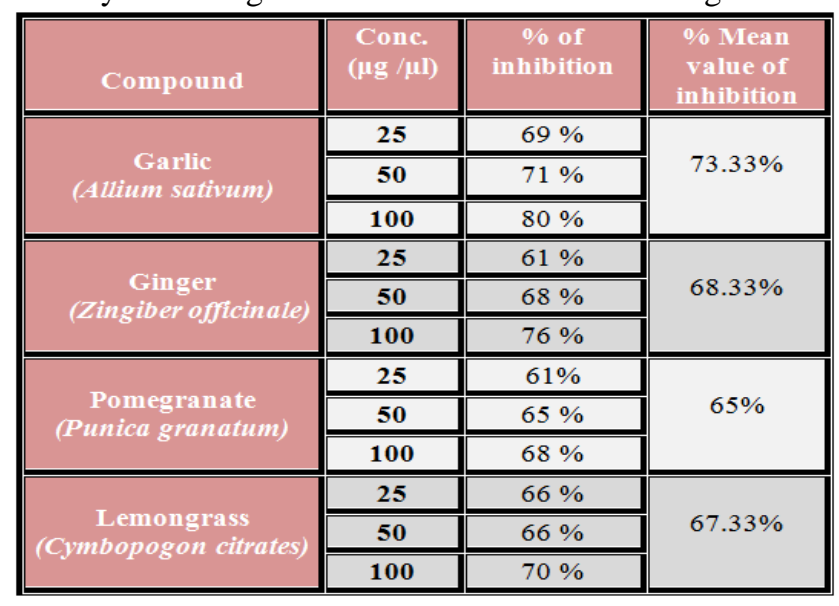




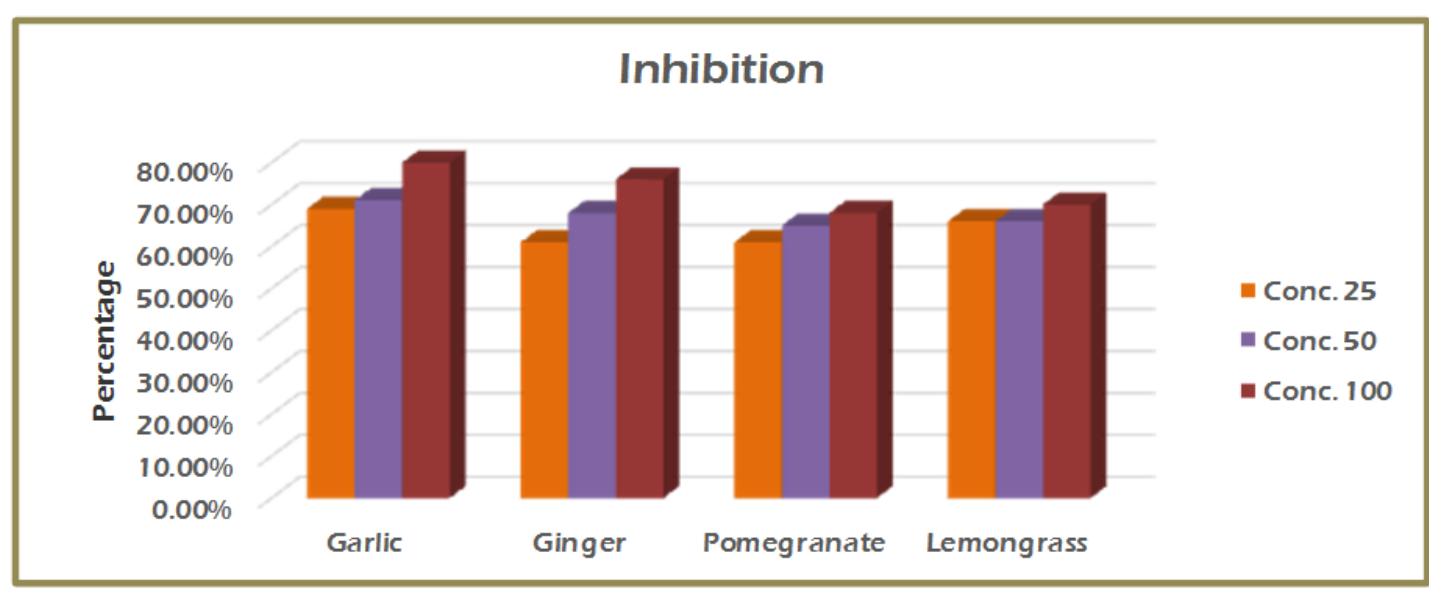

Figure 1. Inhibitory effect of the studied plant extracts on rotavirus SA-11 on MA-104 cell line.

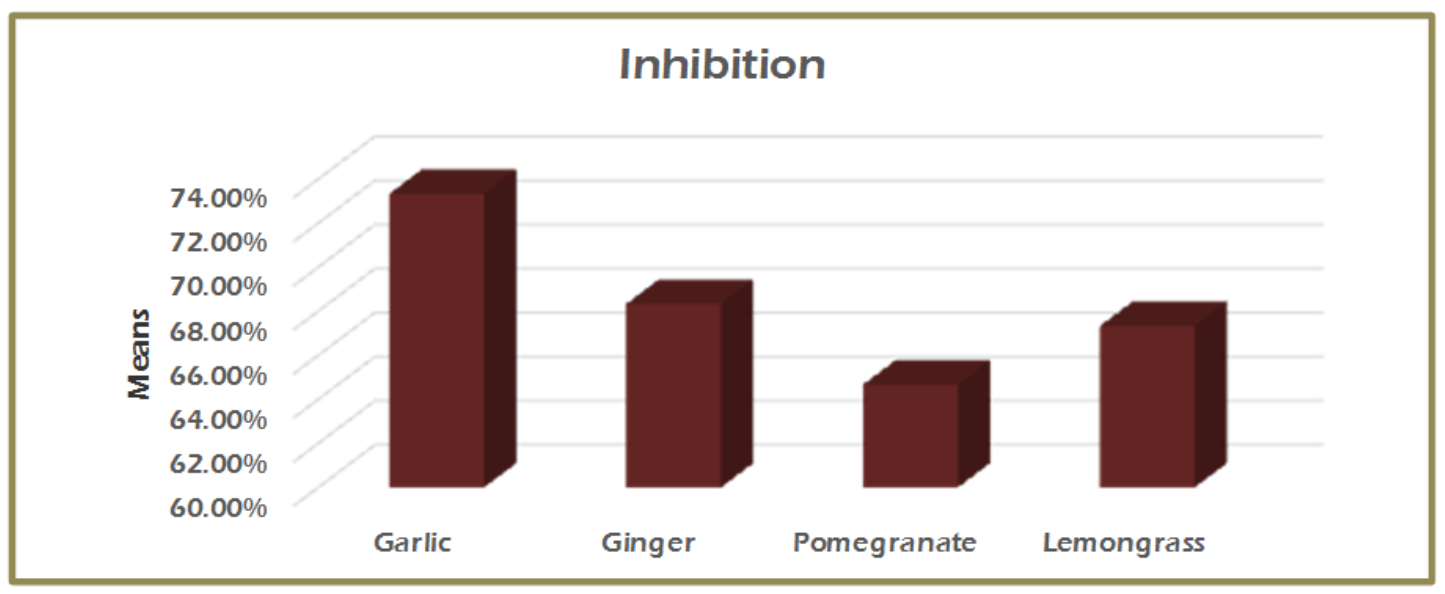

Figure 2. Means inhibitory effect of the studied plant extracts on rotavirus SA-11 on MA-104 cell line. 